\title{
Governance and Management in the Business of Sport
}

\author{
Roberto Cafferata ${ }^{*}$
}

\begin{abstract}
Sport activities and the environment around them are widely considered as being important examples of the emerging service economy, which cultivates strong ties with both the financial and the industrial sectors.

Sports are social economic activities where developments indicate the existence of a dynamic process.

In the global competitive context, sport organisations no longer require generalist managers who can turn their hands to everything, but rather they need managers with the ability to co-ordinate and control complex administration, delegate functions and motivate people. The role of marketing is steadily growing within a sport organisation's business strategies.
\end{abstract}

Keywords: Governance of Sport Organisations; Management of Sport Organisations; Sport Business; Sport Associations; Sport Organisations; New Sports and Old Sports; Superstar-Athletes; Sponsors

\section{Changes in Sport Activities}

Many social activities involving men and women were once considered uneconomic and not comparable to manufacturing and service industries in an open market. Such activities are beginning to come into their own and are developing as producers of income, employment and economic development.

Educational and cultural activities and typical leisure activities such as sports, theatre, cinema and tourism are all growing into a subsystem of increasingly interrelated operations in which resources are invested, work opportunities are created and economic power is both created and propagated. Sport activities and the environment around them are widely considered as being important examples of the emerging service economy, which cultivates strong ties with both the financial and the industrial sectors. Economic literature is focusing ever-greater attention on development trends in sport activities and organisations. We acknowledge the contribution made in the papers edited by Zimbalist (2001) and the work carried out by Slack (1997), Chelladurai (2001), Mahony and Howard

*Full Professor of Management, University of Rome-Tor Vergata (roberto.cafferata@uniroma2.it) 
(2001), Pitts (2001), Sandy, Sloane and Rosentraub (2004) in demonstrating how significant the interest is by economists and scientists in sport economics and management. They have also made an important contribution to the promotion of economic culture within the rather underdeveloped sport organisation world.

Sports are typical leisure activities deeply rooted in the social system and intrinsically linked to the everyday life of both individuals and groups. Still, sport has also become a market. For the second part of the twentieth century at least, sport activities experienced pressures from a broadening economic environment. A new hybrid industry emerged (sport business), which was populated by sporting event organisers, sport sponsors of all kinds and sport equipment manufacturers offering goods, equipment and plant to sport organisations, individual athletes and a large consumer mass market.

The sport market has become not only larger, but also significantly more differentiated. In answering the questions: 'Who produces sports? Who demands sports? i.e. Who is the real consumer of sports in that market?', we realise how complex the market we are concerned with is.

We can distinguish between the producers of regular sport activities (occasional matches, daily training), that is to say amateurs, and the producers of rationally organised events (tournaments, championships), that is to say professionals. Both the former and the latter may give birth to or take part in sport organisations, which may be part of various federations and/or leagues. Both of these supply sport to the social system and the economy (Table 1).

Table 1: Supply and Demand in the Sport Market

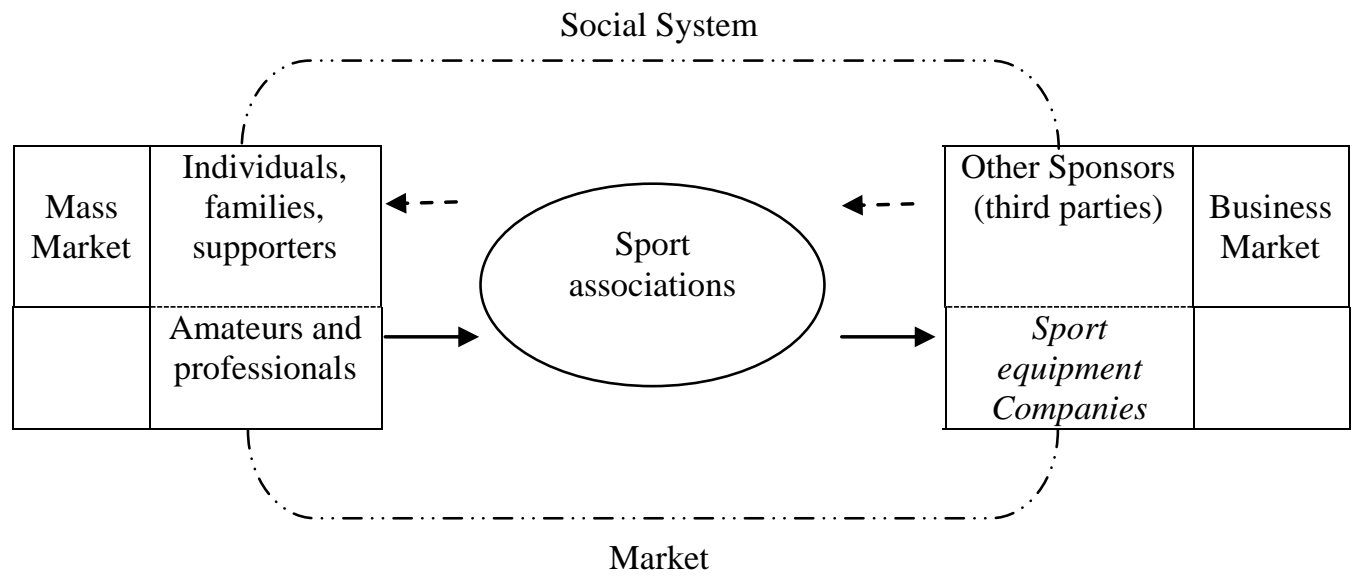

From a demand perspective, we can distinguish between the mass market and the business market.

The mass market includes active and passive supporters of sport associations or sport companies - individuals and families in search of leisure interests to occupy their free time, the previously stated amateurs and professionals who demand goods and services for their occasional matches or for more organised events. All of these people can be seen as consumers of sport activities.

The business market consists of manufacturers of goods for both professionals and amateurs (they are defined as 'sport equipment companies'), advertising agencies, newspaper and publishing companies, multimedia companies and other information service providers, facility suppliers and a large number of companies operating in a 
variety of commercial and industrial sectors (we shall name them 'third parties') that provide the support and sponsorship necessary for sport activities. These third-party companies avail themselves of sport' professional activities and most importantly competitions to reach the general public in order to increase their brand and product market penetration. All these industrial and financial organisations demand sports: without sport they would either not exist or would have a lesser market share (Wilber, 1988; MacDonald, 1991; Marshall \& Cook, 1992).

The organisations that perform and manage sport activities can be considered as intermediaries between the mass market and the business market (see Table 1).

This complex developmental process has resulted in a specific need to ensure a managerial approach to the way in which sport activities are planned and supplied, and how sport organisations behave specifically. There is a widely held belief that sport activities need to be run as a business. The amateur sport teams of yesterday have grown into the associations and companies of today, competing with one another as much in the field of sport as in attracting financial resources. They are characterised not only by routine operations, but also by creative strategies that include interacting shrewdly with suppliers, improving relationships with the media and the general public and providing quality services to satisfy specific customers.

Large sport organisations not only sell tickets in relation to specific games and matches, they also do merchandising, that is to say they sell sport paraphernalia and customised goods to their fans and other customers (Evans, James \& Thomes, 1996; Mahony \& Howard, 2001). Revenues from market operations of this type grew particularly strongly in the nineties, but have rather stagnated since the start of the new century. In the year 2000, revenues from sponsorships and merchandising accounted for $25 \%$ of total annual revenues for a large sport organisation such as Manchester United and almost 15\% for a famous baseball team such as the Yankees (Business Week, 12 October 1998, p. 12; The Economist, 10 February 2001, p. 37).

In conclusion, the most significant change occurring nowadays is the emergence of a new relational field in the economic system, where seemingly different organisations interact, co-operate and share a common interest so as to make a profit. At a time and in a world where many markets are in decline and perish, and where many economic initiatives can be seen to vanish, new capital is being invested both in and around sports, new work organisations are being created and added wealth generated (Vogel, 1994; Go \& Pine, 1995; Lombardi, 2003; Weesterbek \& Smith, 2003). Sports are social economic activities where developments indicate the existence of a dynamic process well known in organisation theory: whenever organisations are created and grow, greater 'promotional opportunities' appear; whenever these organisations decline, the 'opportunity structure' is diminished (Hall, 1987).

In the following section we describe the most significant features of emerging trends in the sport market - particularly in the business market - and the most important organisational innovations in the new relational field. 


\section{Co-ordination and/or Integration of Different Sports Production Functions}

Some preliminary definitions are needed in order to gain a thorough understanding of existing inter-organisational relations, in particular between sport producers, distributors and sponsors (Pepe \& De Franceschi, 1998). As stated above, individual athletes, players, sport associations and companies are considered to be direct producers of sport services at both the entertainment and competitive levels. Governing sport bodies such as federations, leagues and Olympic committees are considered to be indirect producers, providing services for the planning and organisation of championships and major events, and sometimes for the coordination of external sport activity relationships with particular regard to the financial and entertainment implications of these activities.

This type of sport producer must not be confused with the types of sport equipment producers, which represent a category of suppliers of goods and equipment for sport organisations, professionals and individual players. These producers may offer their goods and services to an indistinct consumer market, and sometimes they act as sponsors, too.

Sport producers need real and virtual channels by which to communicate and distribute their specific output to the public. Sport distributors are not only for profit intermediaries - such as the mass media and companies managing sport facilities but also non-profit organisations such as educational and cultural institutions. They make it part of their mission to promote sport at the social level amongst the young and the very young. Indeed, universities and secondary schools in Anglo-Saxon countries are not merely responsible for developing sport habits, but are also sometimes direct producers of sports, thereby nurturing champions.

Sportswear and sport equipment manufacturers are traditional player and sport organisation sponsors. As we know, all other types of manufacturers and providers of goods and services may also become sponsors of sport organisations and individual athletes.

Over the past 20 years, sport production, distribution and sponsorship have coordinated operations in a variety of ways. Co-ordination may take place in three ways.

Informal co-ordination, e.g.: i) a small television network or a well-known print media operator (e.g. the daily Tuttosport in Italy) is typically particularly close to a leading soccer club (e.g. Juventus) and shows bias to that team in its media output; ii) an industrial entrepreneur is a fan of a particular sport and occasionally gives financial support to a team or a club, so that both his company and the sport organisation appear to be engaged in a kind of joint venture.

- Co-ordination through contracts, e.g.: a company producing consumer durables not only may become a formal sponsor of a sporting enterprise having national and international fans, but may also invest money as a minority shareholder in that enterprise. If the same company owns a TV channel, it may also provide for media coverage of the club's matches and obtain greater market penetration for its own particular brands.

- Co-ordination through capital control, e.g.: in such cases, the company taking control of a sport organisation may be either a multimedia company or a company doing business in the entertainment world. The controlling company exploits the sport organisation's sporting activities (e.g. a top soccer club) and 
creates a new channel dedicated to the sport and team that it is nurturing. Hence, it tries to integrate sport events into a complex entertainment package, thereby hopefully widening its public audience.

In Italy, a high profile case is Mediaset, an information and communications technology company with major interests in the top soccer club Milan AC. Mediaset provides a good example of the successful integration of different organisations into a group of companies operating in the entertainment market. The Benetton Group provides a second worthy example of how it is possible to integrate different economic functions and organisations into a complex system (Cafferata \& Mercuri, 1998). This case refers to sport production through the Benetton Basketball and Sisley Volleyball teams, sport event distribution through the facilities of 'Città dello Sport' in Treviso, and the sponsoring of sport organisations, players and events through the Benetton textile company itself.

This kind of co-ordination between production, distribution and sponsorship leads to the formation of complex business organisations interacting with a broadly based public and with national and sometimes global consumers. It is from this type of formal organisation that co-ordination has evolved into a vertically integrated or quasi-integrated production function (Blair, 1972; Richardson, 1972; Hay \& Morris, 1974). Sometimes a company with borders that are very close to sport business and that operates either upstream or downstream, enters the sport business or takes control of a sport organisation. Alternatively, a third party company enters the sport business from a sector well removed from the new business, thus diversifying its activities. The strategy may imply either a radical or marginal shift in investment profile. The first case is related diversification; the second is unrelated diversification (Rumelt, 1974).

Whatever the strategic choice, the successful final result is control of a sport organisation and/or a sport business by a larger company that, though based in different industries, is interested in growth within its global market operations. Large organisations seem to be in a better position than individual entrepreneurs to promote change or respond to innovation issues. In Williamson's terms (1986, p. 94), a vertical or diversified company investing in sports may be the best option for facing and resolving the issue of 'information impactedness'.

\section{Entry of Multimedia Companies into Sport Business}

Indeed, the macro trend under discussion has two quite different aspects (Baux, 1991; Meenagham, 1991).

\subsection{Differentiation}

This implies the consideration of some important changes in the specific products and services of multimedia companies. While their core business is dedicated to providing information, films, soap operas and other entertainment services, these 
large companies are focusing increased attention on broadcasting sport events such as matches, races and championships, that entails distributing normal output from sport organisations (not necessarily from controlled organisations). By making sport events a focal point in their programming, they succeed in maximising their global audience share and revenues. This trend toward the differentiation of multimedia company output is growing in the new century.

Sports became the principal driver of pay-TV in Europe and in particular in the United Kingdom in the nineties. Nowadays, some multimedia companies specialise in broadcasting sport championships and single-sport events.

Rupert Murdoch's BskyB has become the leading buyer of soccer broadcasting rights in Europe having taken over completely from staterun channels. Through its DTH platform, Sky has been able to dictate programming terms of trade to cable operators in Europe (The Economist, 20 June 1998, p. 81).

The advent of pay-TV has created new opportunities not only for the companies that control channels, but also for sport organisations - especially soccer clubs - at the centre of the televised event. These organisations will certainly survive and grow, not only through the ticket office and the sale of players, but also and most of all by selling the broadcasting rights for matches with which they are involved both at home and abroad (Lannevere \& Tempestini, 1997; Morrow, 1999).

As far as soccer is concerned, the selling price for the rights to broadcast an event grew immensely during the nineties and brought about rapid change in revenues for the top clubs.

$\square$ In the United Kingdom, it was estimated that the twenty major Premier League soccer clubs received approximately 650 million pounds from Sky TV between 1997 and 2001. It was satellite coverage of the Premier League that lead Manchester United to reach the highest level of fan support both in Europe and outside Europe (The Economist, 10 February 2001, pp. 37-38). Murdoch's Sky TV also went into the broadcasting market for American football games through Fox by signing a \$1.6 billion contract with the National Football Conference, a contract formerly held by CBS (The Economist, 6 June 1998, p. 16).

Soccer in Europe, baseball and basketball in North America are the biggest money machine for pay-TV operators. Alternatively, minor sport can represent a niche market for entertainment-based companies trying to capture new demand segments and customize their services in order to complete their offering to the public.

\subsection{Diversification}

A second feature of the new market opportunities created by sport is represented by the strategic change by major multimedia companies from service differentiation to production diversification (Cherubini \& Canigiani, 2000). While maintaining their core information and communications business, the larger-sized companies have 
diversified into sport businesses and carried forward their financial interests to the point of gaining control of leading sport clubs.

$\square$ In Italy, the case of Mediaset is very familiar. As stated previously, Mediaset has prominent interests in the top soccer club Milan AC. In the United States, the obvious case to mention is Time Warner. While maintaining its core entertainment and media business, this group has diversified and entered the sport business by acquiring control of baseball and basketball clubs such as The Braves and The Hawks. Then there is Walt Disney, which controls the Angels, a Californian baseball club. Disney also has a 25 per cent share in a hockey club, the Mighty Ducks. However, the multimedia giant seems to be disappointed by the meagre return on its investment and is looking for a buyer for its interest in these baseball and hockey companies. This case confirms that diversification is a costly and very risky strategy for every company (Blair, 1972; Grant, 1994; Hamel \& Prahalad, 1994), even for entertainment and multimedia companies.

Disney's diversification into the sport business has also focused on advertising and/or promoting tournaments in emerging sport such as golf. Moreover, Disney completed the construction of a $\$ 200$ million sport venue at the company's Orlando amusement park in Florida, where recreational sport such as track races are a new attraction for young people. Altering the organisation of sport events to match other leisure and tourism activities could be the right strategic choice for Disney, which is engaged in an amusement park business restructuring.

Well-known but very different cases of diversification relate to the entry of various textile and footwear companies into the sport business. In Rumelt's terms (1974) this is a kind of diversification that is very 'related' to the core clothing production. This kind of entry into the mass market is a strategy implemented by such large industrial companies as Lacoste and Fila, which are both sport equipment companies and sponsors of players, teams and events. For Benetton, which has been in the mass sport market for many years, entry into the sport business market has only been a matter of differentiation from its original products. Benetton has diversified either by sponsoring sport organisations (i.e. basketball or volleyball teams) and 'unique' sport events such as motor racing (Formula 1), or by entering new economic sectors such as motorways (through Autostrade per l'Italia SpA), toll-road food services and catering (through Autogrill SpA). These are cases of a more radical strategy shift: in Rumelt's terms these are cases of 'unrelated' diversification.

\section{Structural Transformation of Sport Venues and Stadiums}

Another important aspect of the increasing integration between sport production and distribution channels is the conversion of sport facilities (football stadiums, sport arenas, tennis grounds, etc.) into kinds of entertainment and tourism resorts. People either compete or play there and spectators not only watch sports but can 
also buy refreshments, find accommodation or even go shopping - places where people can socialise. It can therefore be said that these new multifunctional sport facilities tend to provide entertainment on a very wide scale that is designed to satisfy very different customer expectations (Stone, 1990; Vogel, 1994).

The trend is somewhat similar to that observed in relation to amusement parks: the interest shown by Walt Disney in sports in order to support its commercial and tourism activities was indeed anything but accidental.

Everywhere in the world, major soccer, basketball and volleyball clubs are involved in the radical conversion of the sport grounds they either own or hire into complex sport facilities with the aim of improving the organisation not only of what they offer, but also of the distribution of the outputs of their activities.

In Europe, Chelsea Village - owner of the soccer team of the same name constructed a hotel, apartments and office blocks on the site where the soccer stadium is located, i.e. in the western suburbs of London. Rather strangely, in Italy - one of the homes of soccer - Reggiana is the only team to own a stadium (Cherubini \& Canigiani, 1998). Similar sport facility restructuring and conversion projects are to be observed even in the sport installations at the busiest ski resorts (Business Week, 25 March, p. 60 A-E).

$\square$ In the U.S., more than one city has seen referendums approving the construction of new multifunctional stadiums. This has occurred in San Diego, Denver and Pittsburgh (The Economist, 31 May 1997, pp. 6365; The Economist, 13 March 1999, p. 63).

Tourism and real estate developments of this kind require co-operation by a range of private and public organisations. This implies the allying of sport organisations with councils and mayors, mostly when new projects are part of downtown rejuvenation investment (Crompton, 1995; Siegfried \& Zimbalist, 2000). Should this phenomenon become more widespread, it would transform the budgets of leading sport associations and companies, which would become wealthy through financial and real estate investments quite extrinsic to traditional sport assets, that is, to the value of players and traditional sport plant and equipment.

The interests of divergent companies may converge to invest in a particular sport facility. Allied with sport organisations, can be found multimedia and entertainment companies, advertising companies, and other 'third-party' companies - operating in diverse economic environments - which see in the sport business a way of vertically integrating and/or diversifying their normal product offerings. An interesting example of this kind is represented by the convergence between two different companies, Philips (electronics) and ABN Amro Bank (financial services), allied with Coca-Cola (food and beverage), in a joint venture that invested over $\$ 45$ million in the Amsterdam multifunctional stadium, Arena. This investment resulted not only in the construction of an innovative sport venue, but also in the radical transformation of the Dutch sport ground into a place of entertainment for the public at large.

New developments in real estate and building investment in Hanover, Germany, are a smaller-scaled example of the same, but they still merit our consideration. Exhibition spaces and facilities were created to also host important sport events. During the year 2000 Exhibition, the exhibition space and facilities hosted the 
International Masters of Tennis. A typical day in the life of a tennis spectator entailed the use of commercial services and a visit to the stands and trade fairs. One entrance ticket provided access to matches, parking lots, fitness centres and other entertainment sites for the entire duration of the event.

The management of structures of this kind is complex. The companies involved in such businesses must be extremely careful not to oversize the leisure and tourism facilities, or their investment is inevitably burdened by maintenance costs.

Moreover, the use of stadiums and other sport meeting venues may be discontinuous. Indeed, sport events do not have an infinite life cycle. Investors have to strengthen their marketing strategies to stimulate demand. From the investor's and facilities owner's point of view, it is essential to attract different players and spectators. Event planning must consider not only one single year, but also the long term, with diverse output and different kinds of public.

\section{Sport Organisations: from Associations to Joint Stock Companies}

Professional and organised sport, which is involved in the economic processes stated above, need the support of new legal forms and management methods. At present, sport production within organised structures is characterised by three fundamental changes.

Change no. 1. Groups of people linked by a common passion for a sport discipline, a host of sport associations or even very small clubs may decide to transform themselves into either limited companies, co-operatives or joint-stock companies. Some important soccer clubs are even listed on the stock exchange. From Manchester United in the UK to Lazio in Italy, this phenomenon spread in the nineties. A stock exchange listing is not only a means to obtaining financial resources and enable the transfer of property rights, but also a feature of the company's marketing mix. A listed sport company indirectly helps its athletes and managers to boost their visibility. In Europe at present, the stock exchange listing of sport companies is, however, a declining phenomenon due to the economic disequilibrium of these listed companies. This makes it impossible to both reward the shareholders and improve or even preserve share value. Malcom Glazer, an American financier, took control of Manchester United in 2005 and reached the point that heralded de-listing of the company from the London stock exchange.

Change no. 2. The transformation of once amateur clubs into joint-stock companies has important implications as far as the competition among sport organisations is concerned. As a principle, rival sport companies not only need to compete on the sport ground through their teams, but also have to ensure that the market value of their shares - whether listed or not - improve or at least not suffer in order to prevent undesired reactions from the public, in particular the fans.

Change no. 3. This paper's hypothesis is that boards and managers attach importance to administrative operations - for their part, current and potential shareholders give much greater importance to accountability and reliability in book keeping than before. The company's management is formally required to achieve not only sporting success, but also economic and financial equilibrium for their organisation. A company's good final accounts may not only have economic consequences, but may also influence the performance of the team playing for that 
company. In other words, the economic equilibrium of an organisation can make for better sport. All this requires, or will require further rationalisation in the way sport organisations are conducted. And it is to be expected that the governance of top clubs will no longer be entrusted to sport fans or the scions of elite families, but rather to qualified staff, educated in the best schools or universities.

\section{Competition between New Sports and Old Sports}

New sports come into the world. They compete with old sports, while the latter continue to compete on all fronts among themselves in the way we shall see below.

Golf is often considered new, because it succeeds in attracting players even at the expense of old sports such as tennis. Significant sponsors mean that new disciplines are emerging which were, at least fifty years ago, regarded as negligible or totally neglected. This applies, for example, to wrestling, the sublimation of sport to pure spectacle deriving from media coverage and sponsor support. In Mexico, wrestling (lucha libre) has grown into one of the most popular sports, drawing over 7 million people a year to live matches and many more to TV (The Economist, 11 June 2005, p. 50).

There has always been competition amongst the various sports and amongst the authorities representing sports, all seeking to maximize the number of members and acquire fresh resources from private and public institutions. Competition amongst sports - that is, athletes, clubs, their leagues and/or federations - to gain access to sophisticated and traditional materials, distribution channels (primarily the media) and sponsors increased considerably at the turn of the century. Competition amongst the various sport disciplines has developed in various ways and to different ends, mainly:

a) to attract finance directed at athletes and for individual events (matches, exhibitions, tournaments);

b) to improve the image of an individual sport and gain the largest television network audience share. In the USA, the rivalry between baseball, basketball and football is almost legendary. In Europe, competition between soccer and basketball for supremacy on television networks is growing. Competition has increased sharply within each discipline between women's sports and men's sports. For example, women's basketball and women's volleyball are attempting to get on top of a market biased to the men's game;

c) to find the way out of a crisis. This is the case for tennis and water polo: both sports have to overcome a dramatic loss of image accompanied by lower interest on the part of sponsors, even those textile and shoe manufacturers whose end market has always been amateurs and the general public.

As far as sponsorship competition amongst sports is concerned, it must be pointed out that not all sponsors and not all event distributors such as TV and the press derive positive returns from their investment in sport activities. In the nineties, for example, NBC sustained very high losses in broadcasting tennis matches - even such highprofile important tournaments as Wimbledon's Grand Slam event. Nor did CBS obtain a significant audience by broadcasting the US Open Golf Championship (although current golf fortunes are changing). However, there is still interest in broadcasting 
and/or sponsoring unprofitable sport fixtures, partly because contracts between the sport producer and the multimedia distributor have a precise duration and cannot be terminated abruptly - partly because public taste may change and the loss of today might be the gain of tomorrow.

Finally, we mention the particular market position of companies producing basic sportswear and sport equipment (sport equipment companies). It is only through trialling prototypes that the winning combinations of materials can be found, and this operation requires active player participation. Cooperation amongst different entities is particularly important in athletics, tennis and even swimming or skiing (Business Week, 8 April 1996, p. 60). Not all contracts with individuals or specific teams aiming at testing or promoting innovative materials lead to positive results. Some athletes selected for investment will not continue to be winners over time; hence sport equipment producers tend to change their sporting partners.

\section{Superstar-Athletes, Sponsors and Sport Equipment Producers}

Not only competition amongst sports, but also competition amongst companies is intensifying, mostly as far as the sponsoring of superstars and sport events is concerned. For their part, individual athletes manage budgets as big individual company budgets by winning sponsorships of every kind. The winners - that is, the superstars - behave like small entrepreneurs in an attractive market (Business Week, 28 April 1997, p. 28; Business Week, 16 February 1998, p. 41; Business Week, 25 February 1999, pp. 42-43).

Competition amongst companies to sponsor teams, athletes and sport fixtures is increasing in an attempt to secure not only the promotion, but also the development of particular products. The market is wide open for the industrial and financial support of sport activities. However, the ever-increasing investments demanded by top clubs, athletes and sport events are erecting barriers to entry both by sport equipment companies and 'third parties' into the sponsor market (Baux, 1991; Marshall \& Cook, 1992; Pepe \& De Franceschi, 1998).

Companies that traditionally invest in sponsoring sports are textile, clothing and footwear manufacturers. Sports have been the focus as an opportunity not only for experimenting with new apparel and materials, but also to maintain market share. Consumer behaviour is volatile; design and technology are in a continual state of change. Finely engineered products for sport activities command premium prices and deliver higher margins than generic T-shirts and sneakers.

New specialist sport equipment manufacturers were founded or have emerged in order to satisfy sport producer needs, that is, athlete and sport organisation needs. Sport equipment manufacturers sometimes act as independent suppliers in the mass market. They sometimes work as business units in a group of companies. However, one can identify organisational forms of co-operation between small companies and larger concerns, especially whenever innovative technological or marketing activities - i.e. research on talented players, photography, advertising, electronic commerce - cannot be carried out by a lone company system to the degree of excellence demanded by customers. This is the case for dynamic complementarity amongst companies as suggested by Roy Rothwell (1984). 
Large integrated or diversified companies are progressively dominating the industry, as other sport equipment supply sources are inadequate and cannot offer 'a realistic alternative' (Sutton, 1980, p. 24). Sport equipment companies tend to form an international oligopoly which can be entered only by investing a large amount of financial resources. Nike, Adidas and Reebok are the leading companies. In 2000, after having paid \$200 million to sponsor the Brazilian soccer team, Nike won main sponsorship of the Olympic Games as well. But the most valuable Nike asset is the stable of superstar athletes who promote its brand all over the world, i.e. Tiger Woods, Michael Jordan, Andre Agassi, Roger Federer (The Economist, 4 July 1998, p. 69).

Adidas is competing to regain its position at the apex of the oligopoly after setbacks in the nineties. It succeeded in outmanoeuvring Nike in the rush to diversify from shoes to apparel (Business Week, 21 October 1996, p. 20). By buying the French sport-equipment maker Salomon, Adidas strengthened its position to compete with Nike in North America and Asia, where Nike lost market share (Business Week, 29 September 1997, p. 20). In July 2005, Adidas announced the imminent acquisition of Reebok. In order to protect itself from the emergence of new producers and shift the competitive frontiers, Nike is attempting a radical organisational change from a shoe manufacturing company to a global sports and fitness company, offering a diversified range of products (Business Week, 17 June 1996, pp. 71-72).

\section{Who Governs Sport?}

One of the most significant change trends in the world of sports is observable within the governing bodies of the various competitive disciplines. The National Olympic Committee is the top governing sport authority in almost every country. National federations and sometimes even sport leagues oversee competitive activities within each individual discipline. Clubs, sport associations and companies organise both individuals and groups of athletes who dedicate their lives to sport. However, the way sport activities, matches and championships are governed and run is changing rapidly.

First of all, there is an increasing trend towards self-management, especially in the case of superstars and high-performing players who are deeply involved in their disciplines. Still, enormous financial resources, both personal and from sponsoring companies, are needed to foster self-management. Successful athletes have a market strategy - they manage revenues and costs, surround themselves with technical and administrative staff and cultivate international relationships. Some of them have become a power-brand.

Not only successful athletes, but also less fortunate but hard-working athletes, eventually turn into entrepreneurs when they retire from sports.

Top teams and sometimes sport stars self-manage and self-organise matches, tournaments and exhibitions. There are three international tennis circuits (ATP, WTA and ITF), as well as four Grand Slam Events. Each international organisation represents different economic interests and operates in absolute freedom. Indeed, 
tennis was no more than a follower, that is to say, a mere imitator: superstars and their agents in boxing and basketball were the first movers in developing the concept of self-government with regard to international sport activities (Business Week, 6 July 1998, p. 34).

As the number of opportunities grows within the sport environment, athletes competing internationally have come together and formed associations to operate in the open market, outside the umbrella of traditional sport governing bodies such as national and international leagues and/or federations.

Second, the international sport organisation structure is becoming less hierarchical. In this evolutionary phase to the privatisation of economic initiatives and companies, it is no longer clear who counts most within a certain discipline: the national sport authorities, the major clubs, or even the sponsors commanding huge sport marketing budgets. In 1998, a controversial plan to create a Super League in European Soccer was launched by Mediaset, the owner of Milan AC, a top Italian soccer club. According to that plan, the sport authority which currently runs pan-European soccer (UEFA) would have been abandoned by major European clubs, who would have joined together to form a Super League, running a Super Tournament which would have isolated the Champions League. That plan was not carried out. Still, European soccer is the best candidate to follow the path of U.S. sport professionalism in baseball and football.

A similar trend can be observed in basketball. In June 2005, the news spread that EA Sports, an American business leader in video-games production, might sponsor an intercontinental championship which would be reserved to the best National Basketball Association's teams and to the top European league teams.

Third, there is a push for the creation of new types of federations and/or leagues. In this case, sometimes sport organisations take the initiative; sometimes the best performing athletes promote change. For example, in 2005 a new league was created in Italy with the aim of protecting and developing the interests of the top soccer clubs (that is, the teams playing in 'Serie A').

New sport leagues have been created by women players both in Europe and in the U.S. Sports played by women are becoming increasingly attractive for companies investing in the sport business market (Business Week, 18 January 1999, p. 62). Women superstars are capturing the attention of the media. This is the case with Serena and Venus Williams in tennis. Some women's Grand Slam tennis finals have out-placed men's finals on TV and sometimes TV ratings for women's sport fixtures are higher than for men's events.

To sum up: there is a trend towards polycentrism in sport governance, at least in those disciplines having the largest number of players and spectators (American football, basketball, volleyball, tennis, track and field athletics). There is also a proliferation of authorities at sector level, that is, within a specific sport discipline. For example, in the U.S., volleyball is fragmented into several small leagues.

Even the International Olympic Committee has been steadily changing its attitudes and public relations (Sandler \& Shani, 1989; Emmons, 1996; Chappelet, 2000). Since 1896, this body has governed sports by dictating the guidelines for the development of the various disciplines and by organising the Olympic Games. Its financial needs have obviously grown. Over the past thirty years, IOC expenses have risen to such an extent that the IOC requires financial assistance from global sponsors. The cost of information and communication is particularly significant. It 
has been estimated that some 410 television cameras were used by the various networks covering the 1996 Games in Atlanta, whereas only three were required in Berlin in 1936 (supplemented by an important film documentary produced by Leni Riefenstahl).

The IOC signed contracts with NBC, Eurovision and the Australian networks to ensure coverage of the games until 2008, thus gaining considerable financial benefits. The IOC received about $\$ 3.5$ billion just from one contract with NBC for the rights to broadcast the 2000 summer games in Sydney and the 2002 winter games in Salt Lake City.

\section{Governance and Management of Sport Organisations}

Everything seems to be changing within the sport environment; opportunities are growing for investors. Still, sport producers (that is, sport organisations) are facing difficulties in changing their administrative behaviour. Small and medium-sized clubs, associations, organisations are the natural producers of sports and have been traditionally responsible for the nurturing of players and successful athletes. Nevertheless, while taking care of their natural and technical sport problems, they have neglected governance, management and administrative issues as if these pertained to another world, generally a very specialised world of consultants (Slack, 1997; Acosta Hernandez, 2002).

From this point of view, large sport organisations are not much different from small ones. At the beginning of the new century, a number of top clubs missed profit targets due to rising labour costs, that is the cost of having their champions. Indeed, this is the outcome not only of uncontrolled superstar costs, but also of systematic resource mismanagement. This negative trend nowadays demands a turnaround (Elias \& Dunning, 1994; Defranche, 1997; Piquet, 1998). What this means, in effect, is that sport organisations have to be managed according to rational principles and return to the basic sport ethic. Budget and balance sheets have to be prepared carefully and presented to the associates or partners following discussion by the board of directors. Administrative and sport activities have to be structured and co-ordinated in the same way as a competitive system (Johnson, Kast \& Rosenzweig, 1967; Chelladurai, 2001).

Within individual sport disciplines, top clubs have almost all become either limited companies, or joint-stock companies. They have to achieve economic and financial equilibrium and try to make a profit from their overall operations to satisfy the needs of their owners. Small and medium-sized clubs are under similar pressures to be run professionally, although there are objective limits to growth and organisation structures are simple. The people in charge of these organisations are learning or must learn to think like small entrepreneurs or managers.

They have to cope with new competitive pressures that have grown within the international environment. Even small village clubs are being faced with an open environment and sometimes compete with organisations from foreign countries. No less than in the top sport companies, an efficient organisational structure and innovative technologies are needed in small and medium-sized clubs to make plans, compete with national and international organisations and communicate internally and externally (Cafferata \& Mensi, 1995). Even when a sport association 
or organisation competes only locally or regionally, it is obliged to think in terms of medium-term strategies and design an organisational structure appropriate to the particular strategy chosen.

In this context, plans must not be too complicated. They should be adequately clear in terms of objectives, timescales and control methods. Sport organisations must make plans - on an annual basis at least - to identify priority objectives and build an organisational structure that is not only motivated by sports, but also run professionally in terms of internal and external management. Agreed objectives must be checked against results. Aside from assigning targets to both players and associates, planning and control are managerial activities that help the organisation to improve overall performance and minimise costs (Davis, 1994; Shilbury, 1994; Fullerton \& Dodge, 1995; Chelladurai, 2001).

Another planning and control task is to identify potential revenue sources to cover running costs. Ticket sales are not enough. As stated above, revenues from local and national TV and radio broadcasting rights have become an opportunity and an objective to be maximized. Merchandising is important, too.

Given the new competitive context, sport organisations no longer require generalist managers who can turn their hands to everything, but rather they need managers with the ability to co-ordinate and control complex administration, delegate functions and motivate people. Socially responsible managers should not underestimate the number of players and fans who abandon sports because they are demoralized by the inefficiencies and confusion reigning in the organisation to which they have long been attached. In carrying out their job, managers must not overburden the system with rules and bureaucratic procedures, otherwise the cost of co-ordination and control may become prohibitive and limit the efforts aimed at achieving both the participation of members and equilibrium within the whole organisation.

Once a rational administrative framework has been designed together with an organisational structure appropriate to the competitive environment, a sport company must pay careful attention to everyday operations, the mass market and the business market. In particular, caring for customer needs is an indirect way to take care of the long-terms needs of sport organisation members and financial partners.

Behind the simple questions below are important hidden issues. Not only the most responsible managers, but also the most qualified members of an organisation have to meet (at least once a year) and discuss the following questions:

- What type of demand are we meeting?

- What typical services do we want to supply?

- What fixtures should be organised?

- What additional entertainment services can we offer?

- Should our market be segmented?

- What membership fees should be applied to our associates or customers?

- Where is competition amongst sport clubs going?

Estimates concerning both financial support and investment requirements should be worked out rationally. In this regard, the main issues involved are:

- What sport equipment and installations need to be implemented either immediately, or at set deadlines?

- What parallel structures might be required (cleaning, bodily hygiene, fitness, etc.)? 
- What other comforts should be offered to playing and non-playing members (refreshment facilities, bars, convention centres, games, newsagents, etc.)?

- How do we foster the learning of sports (acquiring coaches, trainers, etc.)?

- Can we recover our costs and particularly the debt costs?

- Should we stress the importance of self-financing and the reinvestment of profits, or take recourse to donors and debt?

In their simplicity - this almost sounds like a pun - the questions outlined above show how complex running a sport activity, together with all complementary operations, can be. Budget assessment, which signals the ability to think in terms of planning and control, and the approval of the final accounts, must grow into central issues for small and medium-sized clubs. Financial account approval is indeed a legal requirement once a sport organisation becomes either a limited company or a joint-stock company.

Larger-sized companies have to consider the preparation of these documents not simply as a formal obligation, but also and particularly as an implication of their growth process. They must see it as an opportunity to enforce the principles of rational management. In smaller-sized companies budget and financial statement preparation should be subject to open discussion, involving not only staff, but also the more active players and athletes. Having a businesslike approach should result in greater understanding of the diversity of the situations to be faced. Implementation of an entrepreneurial approach should not be seen as complicating sport activities; on the contrary, it should be considered as a criterion of efficient management to achieve the objectives close to the heart of both players and supporters (Piantoni, 1999).

The role of marketing is steadily growing within a sport organisation's business strategies (Fullerton \& Dodge, 1995; Evans, James, \& Tomes, 1996; Cherubini, 1997; Pepe \& De Franceschi, 1998; Shannon, 1999; Westerbeek \& Smith 2003). In order to be useful, marketing operations must be related to a sport organisation's market orientation, that is, to the needs to be satisfied and the services and products to be offered.

Market orientation is of a strategic nature (Norman, 1984; Heskett, 1987; Groenroos, 1988; Achrol, 1991). It aims at ensuring that the supply of products and services corresponds to differentiated demand that has to be identified and satisfied. In our opinion, however, a sport organisation can be considered market oriented not only if it is able to differentiate output according to contingencies and customer expectations, but also if it is able to show a clear understanding of the importance of costs/revenues and investment/financing relationships. In other words, to have a market orientation means to be able to define the customer, organise supply in compliance with demand, and plan the economic and financial equilibrium of the organisation.

A sport organisation's marketing plan - including the potential marketing operations - is not a document unto itself, as if it were isolated from the other budgets. The marketing plan must be designed according to the market orientation decided by the Board of Directors of the sport organisation. It is an expenditure as well as a revenue plan. In a sport company the plan sets out investments and costs of personnel, advertising, equipment, organisational structures, commercial channels in relation to the purpose of athletic activities and the desired sporting 
results. At the same time, the plan deals with the issue of revenues, in that it identifies internal sources (fees) and external sources (sponsors, donors) for the coverage of sports and business requirements (Stotlar, 1993). The design and preparation of the plan are a systemic function; demanding collaboration between different parties, that is, associate members, managers, staff and the more involved athletes.

Smaller-sized organisations tend to be rather schizophrenic in their attitude to marketing. Sometimes, they think too big in relation to what is realistically possible to achieve in their sports and commercial activities. Sometimes, they simply remove it from the list of priorities because of inbuilt prejudice. The reason, in the author's opinion, is that they tend to see it in terms of costs only, and not as a planned activity involving both costs and revenues within a survival strategy. Still more widespread in smaller clubs is the lack of market orientation, i.e. the lack of orientation towards business strategies based on market research, the relationship between supply and demand and the pursuit of economic equilibrium for the organisation. As maintained above, the decision-making process is all too often in the hands of people improvising on policies, instead of qualified people or professional managers.

In larger companies, marketing operations are often designed and realized in organisational units of an ambiguous nature. Sometimes, they are drowned in the general administration office: in this context, unrealistic estimates of the facilities and services required for sport activities and events often emerge. To the contrary, marketing operations must be run professionally on the basis of specificity and integrated into a formal strategy. Drowning marketing in a bureaucratised administration is partly due to the lack of financial resources to support the chosen strategies and partly due to the lack of moral conviction that sport organisations should be run as a business and their performance planned and controlled.

\section{Conclusion}

This article has surveyed emerging sport market trends and, in particular, the most important features of the inter-organisational relations in this new competitive field in the international economy.

The major innovations emerging in the new relational field have been determined as follows:

a) Increasing integration between sport producers (sport associations or companies, individual athletes), sport distributors (both the media and other service organisations such as internet companies, advertising agencies, tour operators, schools and universities), industrial and/or financial sport supporters (sponsors).

b) Direct involvement by multimedia companies in setting-up sport events and in the financing and/or control of larger-sized sport organisations: this involvement implies multimedia company production diversification.

c) Conversion of a number of traditional sport grounds into attractive new facilities, where a broad range of entertainment is provided. 
d) Transformation of many sport associations into joint-stock companies, which implies the adoption of management principles largely unknown to these organisations.

e) Intensification of the struggle among different sports, all competing to attract financial resources and gain a foothold in the market.

f) Increased competition among sponsors who provide technical and financial support to individual athletes as well as to sport organisations.

g) New vision of sports matches and races - particularly where superstar athletes and/or top clubs perform - which involves the management of complex events.

h) Multiplication of the authorities governing sports nationally and internationally.

i) Finally, sport organisations are growing in similarity to business organisations (or must increase this similarity) not only when they grow, but also when they want to survive by staying small and efficient in competitive environments. Sport activities are changing in their very nature.

Sports are continuing to grow as a business and the sport business continues to grow. This is a mere statement of fact and a fairly objective description of current trends.

Is that to be considered a good or bad thing? We do not want to take a strong moral stand on this question. Our conclusion is as follows: never was the saying 'to posterity the arduous sentence' as appropriate as to the present situation concerning sports!

\section{Bibliography}

Achrol R.S., Evolution of the Marketing Organisation: New Forms for Turbulent Environments, Journal of Marketing, October, 1991.

http://dx.doi.org/10.2307/1251958

Acosta Hernandéz R., Managing Sport Organisations, Human Kinetics, Champaign, 2002.

Adidas conquista Reebok per battere la regina Nike, Corriere della Sera, 4 agosto, 2005.

Adidas is off and Running, Business Week, October 21, 1996.

An Adrenalin Rush at Adidas, Business Week, September 29, 1997.

Are Stadiums Good for You?, The Economist, March 13, 1999.

A Survey of Sport, The Economist, June 6, 1998.

Baux P., Modèles de persuasion et parrainage sportif, Revue Francaise of Marketing, Janvier, 1991.

Blair J.M., Economic Concentration, Harcourt, Brace, Jovanovich, Chicago, 1972.

Cafferata R., Mensi R., The Role of Information in the Internationalisation of Small and Medium-sized Firms, International Small Business Journal, n. 3, 1995. http://dx.doi.org/10.1177/0266242695133002

Cafferata R., Mercuri M., Gestione e organizzazione professionalizzata delle attività sportive: il caso Verde Sport-Benetton, Economia e diritto del terziario, n. 1, 1998.

Chappelet J.L., Management of the Olympic Games. The Lessons of Sydney, Olympic Review, October-November, 2000. 
Chelladurai P., Managing Organizations. For Sport and Physical Activity, Holcomb Hathaway, Scottsdale, 2001.

Cherubini S., Il marketing sportivo, F. Angeli, Milan, 1997.

Cherubini S., Canigiani M. (ed.), Esperienze internazionali nel marketing sportivo, Giappichelli, Turin, 1998.

Cherubini S., Canigiani M. (ed.), Media e co-marketing sportivo, F. Angeli, Milan, 2000.

Crompton J.L., Economic Impact Analysis of Sports Facilities and Events: Eleven Sources of Misapplication, Journal of Sport Management, January, 1995.

Davis K.A., Sport Management: Successful Private Sector Business Strategies, Brown and Benchmark, Madison, 1994.

Defranche J., Sociologie du sport, Editions La Découverte et Syros, Paris, 1997.

Elias N., Dunning, E., Sport and civilisation, Fayard, Paris, 1994.

Emmons G., Keepers of the Flame. HBS’s Olympic Organiser, Harvard Business School Bulletin, n. 3, 1996.

Evans A., James T., Tomes A., Marketing in U.K. Sport Associations, The Service Industries Journal, n. 2, 1996. http://dx.doi.org/10.1080/02642069600000022

Few Leagues of Their Own, Business Week, January 18, 1999.

Fullerton S., Dodge R., An Application of Market Segmentation in a Sports Marketing Arena: We All Can't Be Greg Norman, Sport Marketing Quarterly, September, 1995. http://dx.doi.org/10.1108/08876049910298775

Glueck W., Business Policy, Strategy Formation and Management Action, McGraw Hill, New York, 1976.

Go F.M., Pine R., Globalisation Strategy in the Hotel Industry, Routledge, London, 1995.

Golden Goals, The Economist, May 31, 1997.

Grant R.M., Contemporary Strategy Analysis. Concepts, Techniques, Applications, Blackwell, Oxford, 1994.

Groenroos J., Service Management and Marketing, Pentium Hall, Uppsala, 1988.

Hamel G., Prahalad C.K., Competing for the Future, Harvard University School Press, Boston, 1994.

Hay D.A., Morris D.J., Industrial Economics. Theory and Evidence, Oxford University Press, Oxford, 1979.

Heskett J.L., Lessons in the Service Sector, Harvard Business Review, March-April, 1987.

It's a Funny Old Game, The Economist, February 10, 2001.

Johnson R.A., Kast F.E., Rosenzweig J.E., The Theory and Management of Systems, McGrawHill, New York, 1967.

Kanter R.M., When Giants Learn to Dance: Mastering the Challenge of Strategy, Management and Careers in the 1990s, Simon and Schuster, New York, 1989.

Lannevere V., Tempestini K., U.K. Football Clubs, Salomon Brothers, London, 1997.

Lombardi P., Sport e turismo: il futuro di due industrie convergenti, Azienda pubblica, n. 1-2, 2003.

MacDonald C., Sponsorship and the Image of the Sponsor, European Journal of Marketing, n. 11, 1991.

Mahony D.F., Howard D.R., Sport Business in the Next Decade: a General Overview of Expected Trends, Journal of Sport Management, n. 4, 2001. 
Marshall D.W., Cook G., The Corporate (Sports) Sponsor, International Journal of Advertising, n. 4, 1992.

Masi P. (ed.), I nuovi beni, Il Sole-24 ore, Milan, 2002.

Meenagham T., Sponsorship: Legitimising the Medium, European Journal of Marketing, n. 11, 1991.

Morrow S., The New Business of Football, McMillan, London, 1999. http://dx.doi.org/10.1057/9780230371743

NBA Players Grab the Ball, Business Week, July 6, 1998.

Norman R., Service Management. Strategy and Leadership in Service Business, Wiley, New York, 1984.

Pele vs. Nike: Guess who won’t Score, Business Week, February 16, 1998.

Pepe C., De Franceschi F., Soggetti e dinamiche di marketing nelle attività sportive, Economia e diritto del terziario, n.1, 1998.

Piantoni G.F., Lo sport tra agonismo, business e spettacolo, Etas, Milan, 1999.

Piquet S., Sponsoring sportif et communication sociale, Revue Francaise de Gestion, Mars-Avril, 1998.

Pitts B., Sport Management at the Millennium. A Defining Moment, Journal of Sport Management, n. 1, 2001.

Richardson G.B., The Organization of Industry, Economic Journal, September, 1972.

Rothwell R., The Role of Small Firms in the Emergence of New Technology, Omega, n. 1, 1984.

http://dx.doi.org/10.1016/0305-0483(84)90007-0

Rumelt R.F., Strategy, Structure and Economic Performance, Harvard University Press, Boston, 1974.

Sandler D.M., Shani D., Olympic Sponsorship versus Ambush Marketing: Who Gets the Gold, International Journal of Advertising Research, August-September, 1989.

Sandy R., Sloane P.J., Rosentraub M.S., The Economics of Sport. An International Perspective, Palgrave, Houndsmills, 2004.

Shannon J.R., Sports Marketing: an Examination of Academic Publications, Journal of Services Marketing, n. 6, 1999.

http://dx.doi.org/10.1108/08876049910298775

Shilbury D., Delivering Quality Service in Professional Sport, Sport Marketing Quarterly, March, 1994.

Siegfried J., Zimbalist A., The Economics of Sports Facilities and their Communities, Journal of Economic Perspectives, Summer, 2000.

http://dx.doi.org/10.1257/jep.14.3.95

Sky's New Dawn, The Economist, June 20, 1998.

Slack T., Understanding Sport Organizations. The Application of Organization Theory, Human Kinetics, Champaign, 1997.

Snowboard Crazy, Business Week, April 8, 1996.

Sport, business, divertimento e moda, Corriere della Sera, 22 giugno 2005.

Stone M., Marketing Strategy for Leisure Services, Long Range Planning, n. 5, 1990. http://dx.doi.org/10.1016/0024-6301(90)90261-2

Stotlar D.K., Successful Sport Marketing, Brown and Benchmark, Madison, 1993.

Sutton C.J., Economics and Corporate Strategy, Cambridge University Press, Cambridge, 1980. 
http://dx.doi.org/10.1017/CBO9780511572241

The Biggest Money Machine in Baseball, Business Week, October 12, 1998.

The Club Med of the Ski Slopes?, Business Week, March 25, 1996.

The Soul of the New Nike, Business Week' June 17, 1996.

Tiger Inc., Business Week, April 28, 1997.

Vogel H.L., Entertainment Industry Economics, Cambridge University Press, Cambridge, 1994

Westerbeek H., Smith A., Sport Business in the Global Marketplace, Palgrave Macmillan, New York, 2003.

Wilber D., Linking Sports and Sponsors, Journal of Business Strategy, n. 4, 1988.

Williamson O.E., Economic Organisation. Firms, Markets and Policy Control, Hemel Hampstead, Harvester Wheatsheaf, 1986.

Yikes! Mike Takes a Hike, Business Week, February 25, 1999.

Zimbalist A. (ed.), The Economics of Sport, Vol. I - Vol. II, Edward Elgar, Cheltenham, 2001 